\title{
Preeclampsia: Postpartum Resolution of Hypertension, Proteinuria and Serum N-terminal B-type Natriuretic Peptide
}

\author{
Vandana Saini ${ }^{1}$, Mamta Gupta ${ }^{2}$, Deepti Sanjay Kumar ${ }^{3}$, Harshvardhan Singh $^{4}$, SK Gupta $^{5}$
}

\begin{abstract}
Background: Postpartum persistent proteinuria and hypertension (HT) is associated with development of chronic kidney disease and cardiovascular disease in later life. AIMS \& OBJECTIVES: To evaluate blood pressure, proteinuria and serum NT-pro-BNP in proteinuric preeclamptic (PE) women and study their postpartum resolution till 3 months and determine the associated risk factors.

Material and methods: 100 PE women enrolled included 66 women with mild (group A) and 34 with severe PE (group B). BP, urinary protein:creatinine $(\mathrm{P} / \mathrm{C})$ ratio, S.NT-pro-BNP were evaluated at labor room admission, postpartum day 1, 6 weeks and 3 months.

Results: Group B women had significant higher baseline BP, urine P/C ratio and S. NT-pro-BNP compared to group A. Resolution of BP, proteinuria and S. NT-pro-BNP was complete in group A women at 6 weeks postpartum. Persistent hypertension was observed in 25 and 4 women at postpartum 6 weeks and 3 months respectively. Proteinuria persisted in 25 and 10 women at postpartum 6 weeks and 3 months respectively. Resolution of NT-pro-BNP was complete at 3 months. In logistic regression model persisting hypertension and proteinuria at 3 months was correlated with increasing age, higher BMI and lower gestational age at delivery. Negative predictive value of $100 \%$ was observed with baseline $\mathrm{P} / \mathrm{C}$ ratio $<5, \mathrm{BP}<120 \mathrm{~mm} \mathrm{Hg}$ diastolic and S.NT-pro-BNP $<1000 \mathrm{pg} / \mathrm{mL}$ for development of persistent proteinuria and hypertension.

Conclusion: Women with severe PE should be followed up for persistent proteinuria and hypertension. These women require evaluation for chronic kidney disease and preventive strategies for cardiovascular disease.

Keywords: Cardiovascular disease, Chronic kidney disease, Postpartum, Preeclampsia, Resolution of hypertension, Resolution of proteinuria, Serum NT-pro-BNP.

Indian Journal of Medical Biochemistry (2019): 10.5005/jp-journals-10054-0104
\end{abstract}

\section{INTRODUCTION}

Preeclampsia (PE), is a pregnancy specific hypertensive disease with adverse feto-maternal outcome. It complicates about $5-8 \%$ of all pregnancies. ${ }^{1}$ Although delivery is the cure for $\mathrm{PE}$, resolution is not immediate. These women have increased risk of cardiovascular disease, chronic hypertension, cerebrovascular and renal disease.

It is well established that pregnancy is essentially a stress test ${ }^{2}$ and the development of pregnancy complications (preeclampsia or gestational hypertension, ${ }^{3-5}$ gestational diabetes or gestational impaired glucose intolerance, ${ }^{6,7}$ clinically significant placental abruption $^{8}$ preterm birth, delivery of a growth restricted or low birth weight baby $^{5}$ ) are some of the earliest clinically identifiable markers for increased risk of premature cardiovascular and renal disease. It has been reported that PE is associated with a 4-fold higher risk for developing remote chronic hypertension. ${ }^{9}$ Women with preeclampsia have a greater than 2-fold risk for fatal and nonfatal ischemic heart disease ( $\mathrm{RR}, 2.26 ; 95 \% \mathrm{Cl}, 1.86-2.52)$, as well as fatal and nonfatal stroke (RR, 1.81; 95\% Cl, 1.45-2.27) ${ }^{10}$. The American Heart Association's 2011 update to their evidencebased guidelines for the prevention of CVD in women now identifies these complications of pregnancy as relevant in the determination of CVD risk in women. ${ }^{11}$

As majority of pregnant women access the health care system on a regular basis, pregnancy is an ideal starting point to determine which women should enter into CVD and renal disease risk screening programs, to identify them to initiate health preservation and disease prevention strategies. As approximately $80 \%$ of cardiovascular disease is largely preventable through lifestyle modification and/or pharmacotherapy; pregnancy and postpartum period provides a window of opportunity for early identification of \begin{tabular}{l}
\hline \hline${ }_{1,2}$ Senior Specialist, ${ }^{3}$ Ex DNB Resident, ${ }^{4}$ Senior Biochemist, ${ }^{5}$ Professor \\
${ }^{1-3}$ Department of Obstetrics and Gynaeology, Hindu Rao Hospital, \\
Delhi, India \\
${ }^{4}$ Department of Biochemistry, Hindu Rao Hospital, Delhi, India \\
${ }^{5}$ Department of Biochemistry, NDMC Medical College, Delhi
\end{tabular}

Corresponding Author: Mamta Gupta, Senior Specialist, Department of Obstetrics and Gynaeology, Hindu Rao Hospital, Delhi, India, e-mail: write2mamta55@gmail.com

How to cite this article: Saini V, Gupta M, Kumar DS, Singh H, Gupta SK. Preeclampsia: postpartum Resolution of Hypertension, Proteinuria and Serum N-terminal B-Type Natriuretic Peptide. Indian J Med Biochem 2019;23(2):278-286.

Source of support: Institutional

Conflict of interest: None

women at risk, and subsequent screening, which would go a long way to improve their long-term health. ${ }^{12}$

For most women, hypertension will resolve within the 1st week postpartum. Hypertension that persists more than 6 weeks postpartum usually represents a pathology not directly associated with pregnancy such as essential hypertension or underlying endocrine, neurological, or renal disease. These women should have their hypertension confirmed with ambulatory monitoring and referred for investigation for a secondary cause for their hypertension. Proteinuria that persists beyond 6-12 weeks postpartum may also warrant further investigation, particularly in early onset preeclampsia, the group of women most likely to have underlying renal disease. ${ }^{13}$

Pro-BNP is secreted by myocytes as a result of myocardial stretch and modulates the cardiovascular system by limiting

() The Author(s). 2019 Open Access This article is distributed under the terms of the Creative Commons Attribution 4.0 International License (https://creativecommons. org/licenses/by-nc/4.0/), which permits unrestricted use, distribution, and non-commercial reproduction in any medium, provided you give appropriate credit to the original author(s) and the source, provide a link to the Creative Commons license, and indicate if changes were made. The Creative Commons Public Domain Dedication waiver (http://creativecommons.org/publicdomain/zero/1.0/) applies to the data made available in this article, unless otherwise stated. 
myocardial hypertrophy, causing peripheral vasodilatation and increasing endothelial permeability. ${ }^{14,15}$ It is further broken down to active hormone BNP and a biologically inactive product NT-proBNP. NT-pro-BNP is a surrogate marker of BNP and has a wider detection rate. Serum NT-pro-BNP levels are higher in pregnant than non pregnant women as a result of myocardial stretch mediated by volume overload. ${ }^{16,17}$ This level is even higher in pregnancy complicated with PE because of increased after-load, superimposed over the pre-existing volume overload and reduced metabolic clearance of NT-pro-BNP due to renal impairment. ${ }^{18}$ It is a better biomarker for predicting mortality, morbidity and hospitalization for cardiac failure, left ventricular dysfunction and coronary artery disease. $^{15}$

Therefore, in this study we have evaluated resolution of hypertension, NT-pro-BNP and proteinuria in pre-eclamptic postpartum women so that affected women would be eligible for preventive therapies at an earlier age.

\section{Aims and Objectives}

1. To evaluate blood pressure and estimate proteinuria and serum NT-pro-BNP in proteinuric preeclamptic women and study their resolution till 3 months postpartum.

2. To determine the risk factors associated with persistence of blood pressure, proteinuria and NT-pro-BNP at 3 months postpartum.

\section{Materials and Methods}

This is a prospective cohort study, conducted in the Department of Obstetrics and Gynaecology of a tertiary hospital and Medical College between May 2015 and May 2017. Approval from ethical committee was obtained. Sample size was calculated as Sample size $(n)=z^{2} P(1-P) / d^{2}$

For $a=0.05$ and $95 \%$ confidence interval, $Z=1.96$

$\mathrm{P}=$ Prevalence of preeclampsia is $8 \%$ approximately in hospital setting (taken as 0.08 ); $d=$ allowable error, taken as $0.05(5 \%)$

Sample size $=1.96 \times 1.96 \times 0.08 \times\left[1-0.08 /(0.05)^{2}\right]=113$

A convenient sample size of 100 women was taken.

\section{InCLUSION CRITERIA}

Preeclamptic women with proteinuria (urine protein:creatinine ratio $>0.3$ ) and willing to participate in the study

\section{Exclusion Criteria}

Women having chronic hypertension, renal disease, severe anaemia, diabetes, thyroid disease, autoimmune disease, cardiac disease, multiple pregnancy, placenta previa

Preeclampsia was defined as BP $>140 / 90 \mathrm{~mm} \mathrm{Hg}$ after 20 weeks on two occasions 6 hours apart or a single reading of $>160 / 110 \mathrm{~mm}$ of $\mathrm{Hg}$, in previously normotensive women. Significant proteinuria was defined as urine protein: creatinine $(P / C)$ ratio $>0.3$. and was a reasonable "rule-out test" for proteinuria above $0.3 \mathrm{~g} /$ day. ${ }^{19}$

One hundred pregnant women in early labor, for induction of labor or scheduled for elective LSCS were enrolled for the study who fulfilled the inclusion and exclusion criteria. Informed consent was taken. All these women were booked cases and were normotensive before 20 weeks of pregnancy. A detailed history, general physical examination, obstetric examination was done at the time of enrollment.

Serum NT-pro-BNP level and proteinuria by spot urine test were estimated in these women. Urinary protein-creatinine ratio and serum NT-pro-BNP levels were again repeated on day 1 postpartum, after 6 weeks and 3 months. BP was recorded at the time of enrollment and was repeated at day 1, 6 weeks and 3 months postpartum.

Plasma NT-pro-BNP measurement was done using Roche CARDIAC pro-BNP kit using cobas $\mathrm{h} 232$ instrument in heparinized venous blood. ${ }^{24}$ It is an immunoassay test using gold-labeled antibodies against NT-pro-BNP which form a sandwich complex with it, in the blood. The sandwich complexes thus formed, gives a visual signal as a red line, the intensity of which is converted to a quantitative result which is read in the display. ${ }^{20}$

Urinary protein: creatinine ratio was estimated in random urine sample specimen (both in $\mathrm{mg} / \mathrm{dL}$ ). Urine protein was estimated by Pyrogallol Red method and urine creatinine by Modified Jaffe's method using automated analyser (Erba EM 360 Autoanalyzer).

Baseline investigations; LFT, KFT, and platelet count were done at the time of enrollment and were repeated at 6 weeks and 3 months. Women were divided into 2 groups. Group A with mild PE and group B with severe PE. ${ }^{21}$

Women in whom proteinuria and NT-pro-BNP resolved at day 1 postpartum, did not have repeat proteinuria and NT-pro-BNP estimation done at 6 weeks and 3 months. Similarly those who resolved at 6 weeks repeat proteinuria and NT-pro-BNP estimation was not done at 3 months. All the data was recorded in a predesigned proforma.

\section{Statistical Methods}

Statistical analysis was done using statistical package for the social science system version SPSS 20.0. The data was presented in terms of number/percentage for categorical variables like age, parity, period of gestation. The various baseline investigations for the two groups was presented as mean+SD. The statistical analysis of quantitative variables between the two groups was carried out by Student $t$ test (parametric test) for data following normal distribution or Mann-Whitney wilcoxan test (non-parametric test) in case data does not follow normal distribution. The significance was tested using Chi- square test/Fischer exact test. Logistic regression models were used to calculate adjusted odds ratio/risk. $P$ value less than 0.05 was considered significant.

\section{Results}

For results refer to Tables 1 to 9 and Figures 1 and 2 .

\section{Discussion}

A prospective observational study to analyze resolution of proteinuria in 100 proteinuric preeclamptic women, a was done. Women were divided into 2 groups mild PE (group $A, n=66$ ) and severe PE (groupB $n=34$ ). Baseline blood pressure, proteinuria (urine $\mathrm{P} / \mathrm{C}$ ratio) and serum NT-pro-BNP and their resolution was observed, during follow up at postpartum day 1, 6 weeks and 3 months in both the groups. Determinant factors for persisting hypertension, blood pressure and NT-pro-BNP at 6 weeks and 3 months postpartum were evaluated through logistic regression models.

In our study mean age, parity and BMI in women was comparable in both the groups, ( $p$ value $0.123,0.206$ and 0.476 respectively). However, mean period of gestation, $\mathrm{S}$ creatinine, blood urea, $\mathrm{S}$ bilirubin and platelet count were significantly lower for women with severe PE compared to women with mild PE ( $p$ value $<0.05$ ). 
Table 1: Demographic details and baseline investigations

\begin{tabular}{|c|c|c|c|c|}
\hline S. No. & Parameter & Mild PE $(N=66)$ & Severe $P E(N=34)$ & Pvalue (test) \\
\hline 1. & Age (mean years) & $26.34 \pm 2.61$ & $27.26 \pm 3.10$ & 0.123 (student $\mathrm{t}$ ) \\
\hline 2. & $\begin{array}{l}\text { Parity } \\
\text { Nullipara }(n=60) \\
\text { Parous }(>1)(n=40)\end{array}$ & $\begin{array}{l}42 \\
24\end{array}$ & $\begin{array}{l}18 \\
16\end{array}$ & $\begin{array}{l}0.206 \\
\text { (Chi square) }\end{array}$ \\
\hline 3. & BMI $\left(\mathrm{kg} / \mathrm{m}^{2}\right)$ & $24.97 \pm 2.37$ & $27.26+3.11$ & 0.478 (student $\mathrm{t}$ ) \\
\hline 4. & POG (weeks) & $37.6 \pm 1.88$ & $35.6 \pm 2.93$ & 0.001 (student $\mathrm{t}$ ) \\
\hline 5. & S. Bilirubin (mg/dL) & $0.88 \pm 0.17$ & $0.77 \pm 0.22$ & $\mathbf{0 . 0 0 5}$ (student $\mathrm{t}$ ) \\
\hline 6. & SGOT (IU/mL) & $27.49 \pm 4.07$ & $27.50 \pm 4.07$ & 0.98 (student $\mathrm{t}$ ) \\
\hline 7. & SGPT (IU/mL) & $24.47 \pm 2.96$ & $24.56 \pm 3.23$ & 0.89 (student $\mathrm{t}$ ) \\
\hline 8. & S. creatinine (mg/dL) & $0.86 \pm 0.161$ & $0.85 \pm 0.165$ & 0.001 (student $\mathrm{t}$ ) \\
\hline 9. & Blood urea $(\mathrm{mg} / \mathrm{dL})$ & $28.15 \pm 3.60$ & $32.21 \pm 9.63$ & 0.003 (student $\mathrm{t}$ ) \\
\hline 10. & Platelets (lacs / mm³) & $1.815 \pm 2.199$ & $1.032 \pm 3.433 .64$ & 0.001 (student $\mathrm{t}$ ) \\
\hline
\end{tabular}

Table 2: Baseline blood pressure, urinary protein: creatinine ratio and NT-pro-BNP

\begin{tabular}{|c|c|c|c|c|}
\hline S. No. & Parameter & Mild PE $(n=66)$ & Severe PE $(n=34)$ & $p$ value \\
\hline 1. & Urinary mean $\mathrm{P} / \mathrm{C}$ ratio & $2.55 \pm 0.73$ & $6.25 \pm 2.64$ & 0.001 \\
\hline 2. & $\begin{array}{l}\text { NT-pro-BNP pg/mL Negative* }(\mathrm{N}=30) \\
\text { Positive }(\mathrm{N}=70) \text {-mean }\end{array}$ & $\begin{array}{l}<60(n=30) \\
88.77 \pm 36.19(n=36)\end{array}$ & $\begin{array}{l}<60(n=0) \\
734.53 \pm 395.62(n=34)\end{array}$ & 0.002 (Mann-Whitney) \\
\hline 3. & BP systolic $\mathrm{mm} \mathrm{Hg}$ & $145.81 \pm 4.88$ & $169.76 \pm 9.21$ & 0.001 (student $\mathrm{t}$ ) \\
\hline 4. & BP diastolic $\mathrm{mm} \mathrm{Hg}$ & $96.60+4.76$ & $122.06+10.88$ & $\mathbf{0 . 0 0 1}$ (student t) \\
\hline
\end{tabular}

${ }^{*}$ NT-pro-BNP levels $<60 \mathrm{pg} / \mathrm{mL}$ was considered negative as it was the maximum upper limit of detection range of NT-pro-BNP.

Table 3: Resolution of postpartum proteinuria, NT-pro-BNP and BP in both the groups

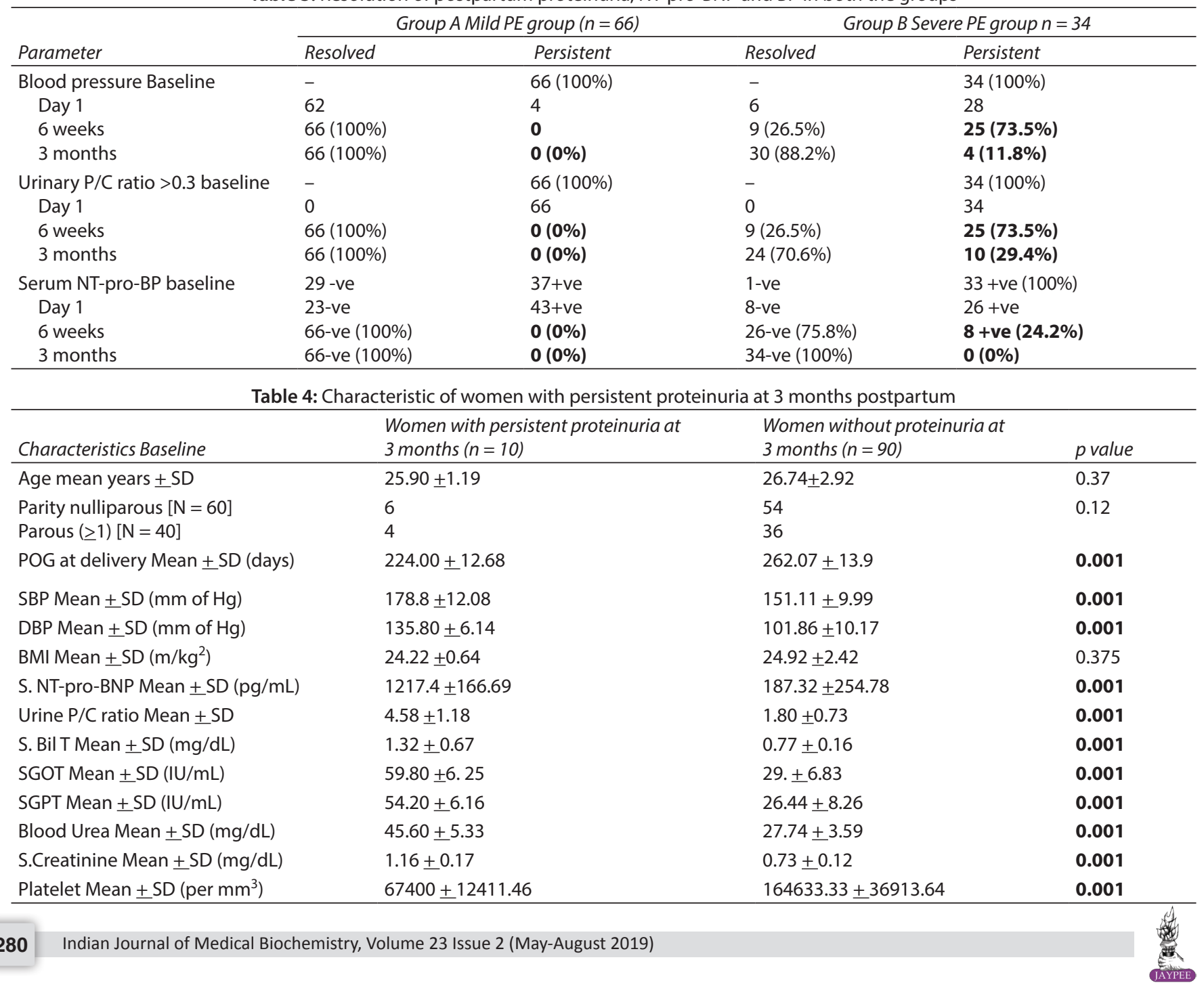


Table 5: Characteristics of women with persistent NT-pro-BNP at 6 weeks postpartum

\begin{tabular}{|c|c|c|c|}
\hline Characteristics baseline & Persistent NT-pro-BNP at 6 weeks $(N=8)$ & Negative NT-pro-BNP $(N=92)$ & pvalue \\
\hline Age mean (years+SD) & $26 \pm 1.51$ & $26.71 \pm 2.9$ & 0.492 \\
\hline Parity nulliparous [N =60] & 6 & 54 & \\
\hline $\operatorname{Parous}(\geq 1)[\mathrm{N}=40]$ & 2 & 38 & 0.376 \\
\hline POG at delivery mean \pm SD (days) & $225 \pm 14.8$ & $261.16 \pm 40.28$ & 0.001 \\
\hline $\mathrm{SBP}$ mean $\pm \mathrm{SD}(\mathrm{mm}$ of $\mathrm{Hg})$ & $177 \pm 14.14$ & $151.86 \pm 11.02$ & 0.001 \\
\hline $\mathrm{DBP}$ mean $\pm \mathrm{SD}(\mathrm{mm}$ of $\mathrm{Hg})$ & $136.25 \pm 6.79$ & $102.56 \pm 11.11$ & 0.001 \\
\hline $\mathrm{BMI}$ mean $\pm \mathrm{SD}\left(\mathrm{kg} / \mathrm{m}^{2}\right)$ & $24.86 \pm 2.34$ & $24.85 \pm 2.32$ & 0.992 \\
\hline NT-pro-BNP mean \pm SD $(p g / m L)$ & $1204.5 \pm 213.16$ & $210.83 \pm 296.35$ & 0.001 \\
\hline Urine $\mathrm{P} / \mathrm{C}$ ratio mean $\pm \mathrm{SD}$ & $4.13 \pm 1.64$ & $1.90 \pm 0.90$ & 0.001 \\
\hline Bil T mean $\pm \mathrm{SD}(\mathrm{mg} / \mathrm{dL})$ & $1.38 \pm 0.74$ & $0.77 \pm 0.17$ & 0.001 \\
\hline $\mathrm{SGOT}$ mean $\pm \mathrm{SD}(\mathrm{IU} / \mathrm{mL})$ & $57.62 \pm 8.83$ & $30.14 \pm 8.63$ & 0.001 \\
\hline $\mathrm{SGPT}$ mean $\pm \mathrm{SD}(\mathrm{IU} / \mathrm{mL})$ & $54.87 \pm 6.17$ & $26.98 \pm 8.99$ & 0.001 \\
\hline Blood urea mean $\pm \mathrm{SD}(\mathrm{mg} / \mathrm{dL})$ & $41.87 \pm 9.84$ & $28.45 \pm 4.99$ & 0.001 \\
\hline Sr. Creatinine mean $\pm \mathrm{SD}(\mathrm{mg} / \mathrm{dL})$ & $1.10 \pm 0.22$ & $0.74 \pm 0.15$ & 0.001 \\
\hline Platelets mean \pm SD $\left(\right.$ per $\left.\mathrm{mm}^{3}\right)$ & $69375 \pm 18133.92$ & $162347.82 \pm 39478.31$ & 0.001 \\
\hline
\end{tabular}

Table 6: Characteristics of women with postpartum persistent hypertension at 3months

\begin{tabular}{|c|c|c|c|}
\hline Characteristics baseline & Persistent $B P$ at 3 months $(N=4)$ & Normal BP at 3 months $(N=96)$ & $p$ value \\
\hline Age mean (years+SD) & $25.250 \pm .50$ & $26.718+2.85326$ & 0.002 \\
\hline Parity Nulliparous [N =60] & 4 & 56 & 0.096 \\
\hline Parous $(\geq 1)[N=40]$ & 0 & 40 & \\
\hline POG mmean \pm SD (days) & $216.25 \pm 17.44276$ & $260.02 \pm 15.03$ & 0.001 \\
\hline $\mathrm{SBP} \mathrm{mm} \mathrm{Hg}$ mean $\pm \mathrm{SD}$ & $184.5 \pm 17.69$ & $152.6 \pm 11.36$ & 0.001 \\
\hline $\mathrm{DBP} \mathrm{mm} \mathrm{Hg}$ mean $\pm \mathrm{SD}$ & $142.0 \pm 4.32$ & $103.73 \pm 12.21$ & 0.001 \\
\hline $\mathrm{BMI}$ mmean $\pm \mathrm{SD}\left(\mathrm{kg} / \mathrm{m}^{2}\right)$ & $23.9125 \pm 0.36262$ & $24.89 \pm 2.35$ & 0.004 \\
\hline NT-pro-BNP mean \pm SD $(p g / m L)$ & $1371.5 \pm 143.03729$ & $245.28 \pm 334.74$ & 0.001 \\
\hline Urine $P: C$ ratio mean $\pm S D$ & $10.36 \pm 1.88$ & $3.54 \pm 2.1$ & 0.001 \\
\hline Bil T mean \pm SD $(\mathrm{mg} / \mathrm{dL})$ & $1.957 \pm 0.61$ & $0.78 \pm 0.17$ & 0.001 \\
\hline $\mathrm{SGOT}$ mean $\pm \mathrm{SD}(\mathrm{IU} / \mathrm{mL})$ & $65 \pm 4.32$ & $30.97 \pm 9.39$ & 0.001 \\
\hline SGPT mmean + SD $(\mathrm{IU} / \mathrm{mL})$ & $54.5 \pm 8.38$ & $28.16 \pm 10.50$ & 0.001 \\
\hline Blood urea Mean \pm SD $(\mathrm{mg} / \mathrm{dL})$ & $49.75 \pm 1.70$ & $28.68+5.19$ & 0.001 \\
\hline S.creatinine mean $\pm \mathrm{SD}(\mathrm{mg} / \mathrm{dL})$ & $1.27 \pm 0.05$ & $0.75 \pm 0.15$ & 0.001 \\
\hline Platelet mean \pm SD $\left(\right.$ per $\left.\mathrm{mm}^{3}\right)$ & $54000+599.01$ & $159114.58+41705.95$ & 0.001 \\
\hline
\end{tabular}

Table 7: Factors associated with persistent NT-pro-BNP, HT and proteinuria at 6 week postpartum

\begin{tabular}{|c|c|c|c|}
\hline Characteristics baseline & Persisting BNP (>60) odds ratio $(95 \% \mathrm{Cl})$ & Persisting hypertension odds ratio $(95 \% \mathrm{Cl})$ & Persisting proteinuria odds $(95 \% \mathrm{Cl})$ \\
\hline Age (years) & $1.109(.827-1.48)$ & $1.13(.863-1.48)$ & $0.843(0.719-843)$ \\
\hline BMI $\left(\mathbf{k g} / \mathbf{m}^{2}\right)$ & $0.998(.730-1.366)$ & $1.15(.841-1.59)$ & $\mathbf{1 . 0 7}(.805-1.18)$ \\
\hline Parity & $0.453(.087-2.36)$ & $0.955(.252-3.62)$ & $0.645(.259-1.60)$ \\
\hline $\mathrm{SBP}(\mathrm{mm}$ of $\mathrm{Hg})$ & $0.836(.745-0.939)$ & $0.442(.178-1.10)$ & 0.749(.656-.854) \\
\hline $\mathrm{DBP}(\mathrm{mm}$ of $\mathrm{Hg})$ & $0.727(.560-0.942)$ & 0 & 0 \\
\hline Urine $\mathrm{P} / \mathrm{C}$ ratio & $0.392(.231-0.664)$ & 0 & $0.068(.014-326)$ \\
\hline NT-pro-BNP (pg/mL) & $0.992(.985-998)$ & $0.602(0-343)$ & $0.826(0-6228)$ \\
\hline Sr. bil T (mg/dL) & $0.056(.009-0.352)$ & $0.034(.005-.225)$ & $0.213(.047-.973)$ \\
\hline Blood Urea (mg/dL) & $0.807(.727-0.896)$ & $0.229(.034-1.54)$ & $0.872(.806-.943)$ \\
\hline Creatinine $(\mathrm{mg} / \mathrm{dL})$ & 0 & 0 & $0.0019(.00-.027)$ \\
\hline SGOT (IU/mL) & $.827(.749-0.914)$ & 0 & $0.546(.378-.788)$ \\
\hline Platelets (per $\mathrm{mm}^{3}$ ) & $1(1-1)$ & 0 & 0 \\
\hline SGPT (IU/mL) & $.769(.635-0.931)$ & $.763(.634-.917)$ & $0.4269(.219-.827)$ \\
\hline POG at delivery & $1.18(1.06-1.32)$ & $1.65(1.05-2.58)$ & $1.095(1.053-1.130)$ \\
\hline
\end{tabular}


Table 8: Factors associated with postpartum persistent hypertension and proteinuria at 3 months

\begin{tabular}{|c|c|c|}
\hline Characteristic baseline & $\begin{array}{l}\text { Persistent Proteinuria } \\
\text { Odds (95\% confidence interval) }\end{array}$ & $\begin{array}{l}\text { Persistent hypertension } \\
\text { Odds (95\% confidence interval) }\end{array}$ \\
\hline Age (years) & $1.13(.863-1.48)$ & $1.29(0.792-2.10)$ \\
\hline BMI $\left(\mathbf{m} / \mathbf{k g}^{2}\right)$ & $1.15(.841-1.59)$ & $1.25(0.736-2.12)$ \\
\hline Parity & $0.636(.172-2.35)$ & $0.655(.08-4.85)$ \\
\hline $\mathrm{SBP}(\mathrm{mm}$ of $\mathrm{Hg})$ & $0.442(.178-1.10)$ & $0.789(.641-.970)$ \\
\hline $\mathrm{DBP}(\mathrm{mm}$ of $\mathrm{Hg})$ & $0.002(.00-1.98)$ & 0 \\
\hline Urine $\mathrm{P} / \mathrm{C}$ ratio & $0.453(.033-1.52)$ & $0.205(.037-1.14)$ \\
\hline S.NT-pro-BNP (pg/mL) & $0.602(.00-4913)$ & $0.611(00-9480)$ \\
\hline Sr. bil T (IU/mL) & $.034(.005-0.225)$ & $0.011(.001-.136)$ \\
\hline Blood Urea (mg/dL) & 0 & 0 \\
\hline $\begin{array}{l}\text { Sr. Creatinine } \\
(\mathrm{mg} / \mathrm{dL})\end{array}$ & 0 & 0 \\
\hline SGOT (IU/mL) & 0 & $0.648(.402-1.04)$ \\
\hline Platelet (per mm³) & $1(1-1)$ & $1.003(.844-1.19)$ \\
\hline SGPT (IU/mL) & $0.763(.634-.917)$ & $0.814(.574-1.15)$ \\
\hline Gestational age at delivery (weeks) & $1.65(1.05-2.58)$ & $1.21(1.03-1.41)$ \\
\hline
\end{tabular}

Table 9: Predictive values for postpartum persistent proteinuria and persistent $\mathrm{HT}$ at 3 months

\begin{tabular}{|c|c|c|c|c|}
\hline \multirow[b]{2}{*}{ Parameters } & \multicolumn{2}{|c|}{ Persistent proteinuria at 3 months } & \multicolumn{2}{|c|}{ Persistent HT at 3 months } \\
\hline & ${ }^{*} P P V$ & ${ }^{*} N P V$ & PPV & NPV \\
\hline Baseline NT-pro-BNP cut off level, 1000 pg/mL & $100 \%$ & $100 \%$ & $40 \%$ & $100 \%$ \\
\hline Persistent NT-pro-BNP at 6 weeks & $75 \%$ & $93.5 \%$ & $30 \%$ & $100 \%$ \\
\hline Baseline urinary $\mathrm{P} / \mathrm{C}$ ratio, cutoff level 5 & $43.4 \%$ & $100 \%$ & - & - \\
\hline Baseline diastolic BP cutoff $120 \mathrm{~mm} \mathrm{Hg}$ & - & - & $26.66 \%$ & $100 \%$ \\
\hline
\end{tabular}

PPV, positive predictive value; *NPV, negative predictive value

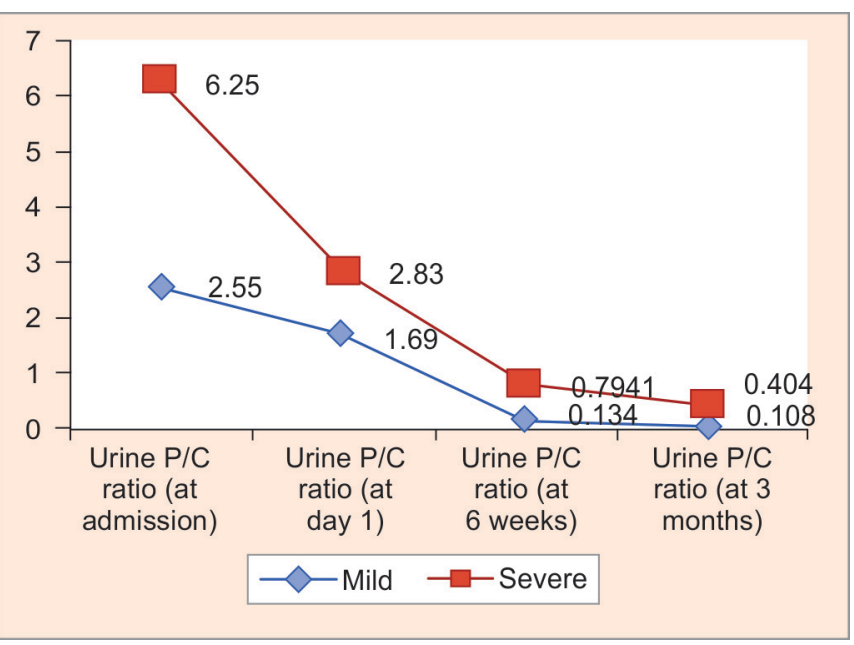

Fig. 1: Resolution of postpartum proteinuria

Base line mean systolic and diastolic BP in group A were $145.81 \pm 4.88$ and $96.60+4.76 \mathrm{~mm} \mathrm{Hg}$ respectively and in group B systolic and diastolic BP were $169.76 \pm 9.21$ and 122.06+10.88 $\mathrm{mmHg}$ respectively. The difference of systolic and diastolic BP between the 2 groups was statistically significant ( $p$ value 0.001 ). The overall resolution of hypertension was $96 \%$ at the end of 3 months, only $4 \%$ women had persistent hypertension. At 6 weeks follow up resolution of hypertension was complete in group $A$ and in only $26.5 \%$ women in group B. At 3 months resolution of hypertension in group B occurred in $88.2 \%$ women. Extrapolating these observations it can be said that women with mild PE does



Fig. 2: Resolution of postpartum serum NT-pro-BNP levels

not require follow up for persistent hypertension. However, women with severe PE should be followed up for persistent hypertension, a risk factor for cardiovascular disease.

The positive predictive value at a cut off at $120 \mathrm{~mm} \mathrm{Hg}$ baseline diastolic blood pressure for development of persistent hypertension at 3 months was found to be only $26.66 \%$ in our study. However, negative predictive value at a cut off at $120 \mathrm{~mm} \mathrm{Hg}$ baseline diastolic blood pressure for development of persistent hypertension at 3 months was found to be $100 \%$. This is a very important observation of our study obviating the need of followup of women with baseline diastolic BP of less than $120 \mathrm{~mm} \mathrm{Hg}$. 
In a study by Berks D et al, $39 \%$ of women had persistent hypertension at 3 months postpartum; which decreased to $18 \%$ at 2 years postpartum. He showed that resolution time increased by $60 \%(P<.001)$ for every $10 \mathrm{~mm} \mathrm{Hg}$ increase in maximal systolic blood pressure, $40 \%(\mathrm{P}=.044)$ for every $10-\mathrm{mm} \mathrm{Hg}$ increase in maximal diastolic blood pressure, and 3.6\% $(P=.001)$ for every 1-day increase in the diagnosis-to-delivery interval. ${ }^{22}$

Contrary to postpartum resolution of blood pressure, Sibai has reported postpartum development of hypertension in some cases. Cause of this postpartum hypertension has been reported to be either benign ie. gestational hypertension or chronic HT or life threatening ie. PE or stroke. ${ }^{23}$

It is observed in our study that age, BMI and gestational age at delivery were significantly lower among women who had persistent hypertension at 3 months after delivery ( $p$ value $<0.05$ ). While mean systolic and diastolic BP, serum NT-pro-BNP levels, urine protein:creatinine ratio and the basic blood investigations ( $\mathrm{Sr}$. Bil T, SGOT, SGPT, blood urea, Sr. creatinine and platelet count) were significantly higher in the persistent group $(p<0.05)$.

In logistic regression model persisting hypertension at 3 months was correlated with increasing age (OR1.29) and higher BMI (OR 1.25) and lower gestational age at delivery (OR1.21) where as no correlation was found with parity, severity of hypertension, urine protein:creatinine ratio and serum NT-pro-BNP levels at admission in our study.

Preeclampsia women have an increased risk of later development of cardio-vascular disease. The relative risks for hypertension were 3.70 after 14.1 years mean follow-up, for ischaemic heart disease 2.16 after 11.7 years, for stroke 1.81 after 10.4 years. ${ }^{10}$

How preeclampsia is related to later development of cardiovascular disease? An explanation given by Bellamy et al is that angiogenic peptides and their endogenous inhibitors have a role in the physiology of preeclampsia and these pathways have been implicated in the development of cardiovascular disease as well. It is possible therefore, that preeclampsia is the initial point of expression of an inherent adverse phenotype associated with the early development of cardiovascular disease. ${ }^{10}$

Changes during healthy pregnancy include insulin resistance, hyperlipidaemia, hypercoagulability, inflammation, and a hyperdynamic circulation. These are exaggerated in women with preeclampsia and some are also "risk factors" for cardiovascular disease. It is possible that preeclampsia increases risk of later cardiovascular disease, either because of a shared cause or because of subclinical vascular damage during preeclampsia. It is possible that transient but severe endothelial dysfunction, observed in preeclampsia, potentiates a cascade of events that progresses to atherosclerosis. Endothelial dysfunction has been observed as early as 23 weeks' gestation in women who develop preeclampsia later, during preeclampsia itself, and at least three months after preeclampsia has resolved. ${ }^{10}$

In our study, the mean NT-pro-BNP levels was found to be significantly high in group $B$ women (mean $734.52 \mathrm{pg} / \mathrm{mL}$ ) compared to group A (mean $112.75 \mathrm{pg} / \mathrm{mL})(p=0.002)$. This observation was similar to Murat Bakacak et al, Kumari $S$ et al who also found NT-pro-BNP levels significantly higher in severe preeclampsia group compared with mild preeclampsia group $(p<0.001) .24,25$

At 3 months postpartum resolution of NT-pro-BNP in both the groups was found to be complete. Persistent serum NT-pro-BNP was observed in eight women at the end of 6 weeks in group $B$. None had persistent serum NT-pro-BNP in group A at 6 weeks postpartum. It was also observed in our study that persistent NT-pro-BNP at 6 weeks postpartum had a $100 \%$ negative predictive value for development of persistent hypertension at 3 months. Therefore, NT-pro-BNP is a very important parameter which can be estimated at the routine 6 weeks postpartum visit and if found to be negative, can obviate the need of postpartum 3 month follow up for detection of persistent hypertension, a risk factor for later cardiovascular disease.

It was observed in our study that gestational age at delivery was significantly lower among women who had persistent NT-pro-BNP at 6 weeks ( $p$ value $<0.05$ ). While the mean systolic and diastolic $\mathrm{BP}$, serum NT-pro-BNP levels, urine protein:creatinine ratio and the basic blood investigations (S. Bilirubin, SGOT, SGPT, Blood urea, S. creatinine and platelet count) were significantly higher in the persistent group ( $p$ value 0.001 ).

In logistic regression model persisting high levels of serum NT-pro-BNP at 6 weeks was correlated with increasing age (OR 1.109), lower gestational age at delivery (OR 1.18). Gestational age at delivery correlated with persistence of NT-pro-BNP, proteinuria and hypertension.

A very important and interesting observation of our study was that baseline serum NT-pro-BNP levels at a cutoff of $<1000$ $\mathrm{pg} / \mathrm{mL}$ had a negative predictive value of $100 \%$ for development of persistent hypertension at 3 months. Thus serum NT-pro-BNP levels at admission can be a useful tool to know which PE women do not need follow up for persistent hypertension. We could not find any study regarding resolution of NT-pro-BNP in postpartum preeclampsia women and its predictive value.

Mean baseline urinary $P / C$ ratio in group $A(2.55 \pm 0.73)$ and group $B(6.25 \pm 2.64)$ had a significant difference ( $p$ value 0.001$)$ in our study. Proteinuria completely resolved in group $A$ at postpartum 6 weeks. In group B proteinuria resolved in only in $26.5 \%(n=9)$ women at 6 weeks and $70.6 \%(n=24)$ at 3 months. Our results signify the need to follow up women with severe PE for persistent proteinuria. Our results are comparable with study by Berks, et al. (2009) who reported persistent postpartum proteinuria in $21 \%$ at 6 weeks and $14 \%$ of women at 3 months. ${ }^{24}$ They followed patients till 2 years and finally at 2 years, $2 \%$ had persistent proteinuria. They have reported resolution time increased by $16 \%(p=.001)$ for every $1-\mathrm{g} / \mathrm{d}$ increase in maximal proteinuria. Gestational age at onset of preeclampsia was not correlated with resolution time of hypertension and proteinuria. ${ }^{22}$

In a prospective study by Francois Kaze et al (2014) involving 54 women with severe preeclampsia and eclampsia 26 (48.1\%), $17(31.5 \%)$ and $1(1.8 \%)$ patient had persisting proteinuria at 6 weeks, 3 months and 6 months post delivery respectively. ${ }^{26}$ This was more than in our study.

Persisting proteinuria is a risk factor for development of chronic kidney disease and subsequent end stage renal disease (ESRD). Prakash J et al reported mean resolution time as 35.8 days (21-90 days). Two women with persistent proteinuria and hypertension beyond 12 weeks were diagnosed as focal segmental glomerular sclerosis (FSGS) and MPGN (membano-proliferative glomerulonephritis) on renal biopsy and histology. ${ }^{27}$ Lioufas $\mathrm{N}$, has reported FSGS in 4 cases following PE pregnancy; 2 at cases 16 weeks, 1 case at 6 months and 1 at 10 weeks postpartum. ${ }^{28}$ Roberts $\mathrm{AL}$ et al studied 9 women having persisting proteinuria at 6 months postpartum, 2 were subsequently diagnosed with $\mathrm{CKD}^{29}$ Ten of 14 patients (71\%) with persistent proteinuria were diagnosed with underlying renal disease in a study by Unverdi etal. Four patients (29\%) were diagnosed with MPGN, four patients (29) 
were diagnosed with IgA nephropathy (IgAN), one patient (7\%) was diagnosed with FSGS, and one patient $(7 \%)$ was diagnosed with amyloidosis. ${ }^{30}$ Thus persistent proteinuria in PE women require further investigations and should not be overlooked.

Though in our study parity was not found to be associated with persistent proteinuria but Vikse $B E$, et al. has reported that $P E$ in women who had been pregnant two or more times, PE during the first pregnancy was associated with a relative risk of ESRD of 3.2, PE during the second pregnancy with a relative risk of 6.7, and $P E$ during both pregnancies with a relative risk of 6.4. Among women who had been pregnant three or more times, PE during one pregnancy was associated with a relative risk of ESRD of 6.3, and PE during two or three pregnancies was associated with a relative risk of $15.5^{31}$

It was observed that gestational age at delivery was significantly lower among women who had persistent proteinuria at 3 months after delivery ( $p$ value $<0.05$ ). While the mean systolic and diastolic $\mathrm{BP}$, serum NT-pro-BNP levels, urine protein:creatinine ratio and the baseline blood investigations (S. Bilirubin , SGOT, SGPT, blood urea, Sr. creatinine and platelet count) were significantly higher in the persistent group.

In the logistic regression models persisting proteinuria in our study was correlated with factors expressed as odds ratio and $95 \%$ confidence interval. Increasing age [OR-1.13,95\%Cl-0.863-1.48)], higher BMI [1.15(0.841-1.59)], and lower gestational age at delivery [OR1.65(1.05-2.58) whereas no correlation was found with parity, severity of hypertension, urine protein:creatinine ratio and serum NT-pro-BNP levels at admission.

Similar observations were made by Kaze et al who reported that advanced age, high BMI, low gestational age at delivery, low fetal birth weight, and proteinuria at delivery were the main risk factors for persisting hypertension at 3 months. Also advanced age and higher body mass index were the only determinants of the composite outcome of persisting hypertension or proteinuria at 3 and 6 months. ${ }^{26}$

Yattinamani BP et al in their study have opined that early gestational age at onset of hypertension and earlier gestation at delivery was associated with slower recovery from hypertension. Time taken for recovery was also associated with age, BMI, severity of hypertension, associated complications, and the number of antihypertensive medications received. Women who received more than 3 antihypertensives in pregnancy, nearly $50 \%$ continued to have hypertension. BMI and time to blood pressure normalization had a strong positive correlation $(r=0.8) .^{32}$

Similar to our study, Berk D, et al. (2009), observed that resolution time of proteinuria was not significantly correlated with parity. He has concluded that higher age, higher BMI and higher baseline urinary protein excretion was associated with increased risk of persisting proteinuria at 3 months [OR8.48(1.36-52.79)]. Severity of $\mathrm{PE}$ and the time interval between diagnosis and delivery were associated with postpartum time to resolution of hypertension and proteinuria. After preeclampsia, it could take up to 2 years for hypertension and proteinuria to resolve and further invasive diagnostic tests for underlying renal disease may be postponed until 2 years postpartum. ${ }^{22}$

Nidyambagye, et al. has opined that nearly one of every four mothers with preeclampsia/eclampsia are at risk of persistent hypertension at the end of the puerperium. Maternal age, serum creatinine and serum uric acid levels are predictors of persistent hypertension after the puerperium in women with preeclampsia and eclampsia. ${ }^{33}$ However, in our study maternal age, BMI and period of gestation at the time of delivery, were the factors associated with persistent hypertension. Serum bilirubin, SGOT,SGPT, S. creatinine, Blood urea, platelets and NT-pro-BNP were significantly increased in women with persistent hypertension.

In our study, baseline urine $\mathrm{P} / \mathrm{C}$ ratio $<5.0$ and baseline S. NT-proBNP less than $1000 \mathrm{pg} / \mathrm{mL}$ had a negative predictive value of $100 \%$ for persistent proteinuria at 3 months. This is a very important observation of our study. Thus obviating the need for follow up of women with baseline $\mathrm{P} / \mathrm{C}$ ratio $<5.0$ and NT-pro-BNP $<1000 \mathrm{pg} / \mathrm{mL}$.

Several mechanisms might explain the observed association between preeclampsia and subsequent renal disease. One possibility is that kidney disease and preeclampsia are caused by the same factors. Obesity, hypertension, insulin resistance, and endothelial dysfunction, have been linked to both disorders. While the definite cause of renal dysfunction in PE remains unclear, one possible mechanism might be damage caused by endothelin, a potent endogenous vasoconstrictor peptide produced by endothelial cells. ${ }^{34}$ The renal insult secondary to vasospasm might be one of several potential factors involved in the pathogenesis of chronic hypertension among these women with PE. Likewise, chronic hypertension and PE may have similar or related risk factors. In women in whom endothelin levels are persistently elevated, serum uric acid is increased and creatinine clearance is diminished. ${ }^{34}$ Antiangiogenic factors have been suggested to have an important role in the pathogenesis of PE and in the progression of chronic renal disorders. It is also possible that some women with PE with subsequent persistent albuminuria had unrecognized renal disease before pregnancy which may have remained undetected or unreported. Hence, PE would be an important clinical marker for an increased risk of renal disease in these women. ${ }^{35,31}$

Because women with a PE pregnancy are at risk of cardiovascular disease and end-stage renal disease, proper follow-up after delivery for resolution of proteinuria and hypertension is required and investigations should be conducted to capture and adequately treat any underlying cardiovascular or renal disease. However, this is not always the case: In 2004, Samwiil et al reported that out of 257 former PE women, at 6 weeks postpartum $6 \%$ had not got blood pressure measured and $68 \%$ had not got their urine tested for proteinuria. ${ }^{36}$

Current guidelines for the follow-up of PE woman, recommend that women to be initially seen at 6 weeks postpartum, and subsequently have annual screening of their blood pressure and urinary protein indices. This 6 week postpartum visit is essential to ensure the resolution of proteinuria and hypertension, to allow for further referral and evaluation. ${ }^{37}$ These women should be evaluated with respect to continuing proteinuria, persistent hematuria, or impaired renal function and a percutaneous renal biopsy should be performed in women who have positive signs of underlying renal disease. ${ }^{30}$

Limitation of our study-We did not study the diagnosis-todelivery interval, but those with early delivery in our group had late postpartum recovery, indicating that they had severe/complicated preeclampsia that had demanded early termination.

\section{Conclusions}

In women with mild PE scheduled follow up for persistant HT and proteinuria are not necessary. Women with severe PE are the candidates who require scheduled follow up for persistent HT and proteinuria. In women with initial S. NT-pro-BNP levels of $<1000 \mathrm{pg} /$ $\mathrm{mL}$, the need for scheduled follow up is not essential. Women with 
initial urine $\mathrm{P} / \mathrm{C}$ ratio $>5$, and baseline $\mathrm{BP}$ of $>120 \mathrm{~mm}$ Hg require scheduled follow up for persistent proteinuria and $\mathrm{HT}$.

However, more studies are required in this regard. We suggest an extended follow-up of these women beyond the postpartum period, particularly the older, those with high BMI and low gestational age at delivery to allow the early detection, investigation and treatment of women who will develop renal or cardiovascular disease. Persistent proteinuria at 3 months postpartum must be investigated and evaluated for a possible underlying renal disease by a nephrologist. Also persistant hypertension beyond 3 months may be evaluated for secondary cause of HT. As they have an increased cardiovascular risk, lifestyle modifications and pharmacotherapy can be started at an earlier stage.

\section{References}

1. Center for Health Informatics (CHI), at National Institute of Health and Family Welfare (NIHFW), by Ministry of Health and Family Welfare (Mo HFW), Govt. of India. Available at https://www.nhp.gov.in/disease/ gynaecology-and-obstetrics/preeclampsia

2. Williams D. Pregnancy: a stress test for life. Curr Opin Obstet Gynecol 2003;15:465-471.

3. Smith GN. The development of preeclampsia provides a window of opportunity for early cardiovascular risk screening and intervention. Expert Rev Obstet Gynecol 2009;4:355-357.

4. Smith GN, Walker M, Liu A, Wen SW, Swansburg M, Ramshaw H, et al. A history of preeclampsia identifies women who have underlying cardiovascular risk factors. Am J Obstet Gynecol 2009;200:58.e1-e58. e8.

5. Smith GCS, Pell JP, Walsh D. Pregnancy complications and maternal risk of ischaemic heart disease: a retrospective cohort study of 129,290 births. Lancet 2001;357:2002-2006.

6. Retnakaran R. Glucose tolerance status in pregnancy: a window to the future risk of diabetes and cardiovascular disease in young women. Curr Diabetes Rev 2009;5:239-244.

7. Retnakaran R, Shah BR. Mild glucose intolerance in pregnancy and risk of cardiovascular disease: a population-based cohort study. CMAJ 2009;181:371-376.

8. Ray JG, Vermeulen MJ, Schull MJ, Redelmeier DA. Cardiovascular health after maternal placental syndromes (CHAMPS): populationbased retrospective cohort study. Lancet 2005;366:1797-1803.

9. Ghossein-Doha C; Peeters L; van Heijster S; van Kuijk S; Spaan J; Delhaas T; Spaanderman M. Hypertension after preeclampsia is preceded by changes in cardiac structure and function. Hypertension. 2013; 62(2):382-390 (ISSN: 1524-4563)

10. Bellamy L, Casas JP, Hingorani AD, Williams DJ. Preeclampsia and risk of cardiovascular disease and cancer in later life: systematic review and meta-analysis. BMJ. 2007;335:974.

11. Mosca, L, Benjamin, EJ, Berra, K, Bezanson, JL, Dolor, RJ, LloydJones, $\mathrm{D}$ et al. Effectiveness-based guidelines for the prevention of cardiovascular disease in women-2011 update. J Am Coll Cardiol. 2011;57:1404-1423.

12. Smith GN, Jessica Pudwell, Mark Walker, Shi-Wu Wen Ten-Year, ThirtyYear, and Lifetime Cardiovascular Disease Risk Estimates Following a Pregnancy Complicated by Preeclampsia. J Obstet Gynaecol Can 2012;34(9):830-835

13. Townsend R, Patrick O'Brien, and Asma Khalil Current best practice in the management of hypertensive disorders in pregnancy. Integr Blood Press Control. 2016; 9:79-94.

14. Weber M, Hamm C. Role of B-type natriuretic peptide (BNP) and NT-pro-BNP in clinical routine. Heart. 2006;92(6):843-849.

15. Rodseth RN. B type natriuretic peptide-a diagnostic breakthrough in perioperative cardiac risk assessment? Anaesthesia. 2009;64(2): 165-178.
16. Franz MB, Andreas M, Schiessl B, Zeisler H, Neubauer A, Kastl SP, et al. NTpro-BNP is increased in healthy pregnancies compared to nonpregnant controls. Acta Obstet Gynecol Scand. 2009;88(2):234-237.

17. Sagie AL, Oz BB, Salpeter L, Celnikier DH, Arad I, Nir A. Plasma concentrations of $\mathrm{N}$-terminal Pro-B-type natriuretuic peptide in pregnant women near labour and during early puerperium. Clinical Chemistry. 2005;51(10):1909-1910.

18. Kale A, Kale E, Yalinkaya A, Akdeniz N, Canoruç N. The comparison of aminoterminal probrain natriuretic peptide levels in preeclampsia and normotensive pregnancy. J Perinat Med. 2005;33(2):121-124.

19. Morris RK, Riley RD, Doug M, Deeks JJ, Kilby MD, Diagnostic accuracy of spot urinary protein and albumin to creatinine ratios for detection of significant proteinuria or adverse pregnancy outcome in patients with suspected preeclampsia: systematic review and meta-analysis. Cite this as: BMJ 2012;345:e4342

20. Christenson RH, Tang WHW. Institute for Quality in Laboratory Medicine Series -Controversies in Laboratory Medicine: Insights Into B-type Natriuretic Peptide and N-terminal pro-B-type Natriuretic Peptide Measurements. Med Gen Med. 2006;8(2):62.

21. Tranquilli AL. Introduction to ISSHP new classification of preeclampsia. Pregnancy Hypertens. 2013; 3(2):58-9. doi: 10.1016/j. preghy.2013.04.006. Epub 2013 Jun 6.

22. Berks D, Steegers EA, Molas M, Visser W. Resolution of hypertension and proteinuria after preeclampsia. Obstet Gynecol. 2009; 114(6):130714. doi: 10.1097/AOG.0b013e3181c14e3e

23. Sibai BM. Etiology and management of postpartum hypertensionpreeclampsia. Clinical Opinion. JUNE 2012 American Journal of Obstetrics \& Gynecology 470-475

24. Bakacak M, Serin S, Ercan O, Köstü B, Bakacak Z, Kiran H. Association of serum $\mathrm{N}$-terminal pro-brain natriuretic peptide levels with the severity of preeclampsia. J Matern Fetal Neonatal Med. 2016 Sep;29(17):2802-6. doi: 10.3109/14767058.2015.1104663. Epub 2015 Nov 23.

25. Kumari S, Gupta M, Vardhan H, Saini V, Gupta SK. NT-pro-BNP: A Biochemical Marker of Maternal Complications in Preeclampsia. JCDR. 2017; 11(11):QC12-16 DOI: 10.7860/JCDR/2017/28713.10855

26. Kaze FF, Njukeng FA, Kengne AP, Ashuntantang G, Mbu R, Halle MP, Asonganyi T. Postpartum trend in blood pressure levels, renal function and proteinuria in women with severe preeclampsia and eclampsia in Sub-Saharan Africa: A 6-months cohort study. BMC Pregnancy and Childbirth 2014 14:134. https://doi.org/10.1186/14712393-14-134

27. Prakash J, Vohra R, Pandey LK, Niwas SS, Behura SK, Singh U. Spectrum of Kidney Diseases in Patients with Preeclampsia-Eclampsia. JAPI • september 2010 • VOL. 58 543-546

28. Lioufas N, Ling J, Jaw J, Mathew M, Jose M, et al. (2016) Does Pre-Eclampsia Predispose Patients to the Development of Focal Segmental Glomerulosclerosis? "The Chicken or the Egg?". J Clin Nephrol Ren Care 2016;2:012

29. AL Roberts, P Loughna, A Ferraro, F Broughton-Pipkin. PMM.27 Unresolved proteinuria after preeclampsia: detecting renal disease. Poster presentations BMFMS: Maternal Medicine

30. Unverdi S, Ceri M, Unverdi H, Yilmaz R, Akcay A, Duranay M. Wien Klin Wochenschr. 2013; 125:91. https://doi.org/10.1007/s00508-0320-8

31. Vikse BE, Irgens LM, Leivestad T, Skjaerven R, Iversen BM. Preeclampsia and the risk of end-stage renal disease. N Engl J Med. 2008;359:800809.

32. Yattinamani BP, Guruvare S, Rai L. Postpartum Recovery Trends in Women with Hypertensive Disorders of Pregnancy. Journal of Clinical Outcomes Management. 2017 February;24(2)

33. Ndayambagye EB, Nakalembe M, Kaye DK.Factors associated with persistent hypertension after puerperium among women with preeclampsia/eclampsia in Mulago hospital, Uganda. BMC Pregnancy Childbirth 10: 12. doi:10.1186/147123931012. PubMed: 20222993. 
34. Clark AB. Plasma endothelin levels in Preeclampsia: elevation and correlation with uric acid levels and renal impairment. Am J Obstet Gynecol. 1992;166:962-968. [PubMed]

35. Munkhaugen J, Bjørn Egil Vikse BE. New aspects of preeclampsia: lessons for the nephrologist . Nephrology Dialysis Transplantation, Volume 24, Issue 10, 1 October 2009, Pages 2964-2967, https://doi. org/10.1093/ndt/gfp341
36. Samwiil L, Mercer C, Jarrett P, O'Malley S; Genetics of Pre-Eclampsia Collaborative Study (GOPEC) Research Midwives. Blood pressure and urinalysis are often omitted in women who have suffered preeclampsia at their six-week postnatal check. BJOG 2004;111:623-625.

37. Task Force for Hypertension in Pregnancy (2013) Hypertension in Pregnancy. The American College of Obstetricians and Gynecologists, Women's Health Care Physicians. 